\title{
Effect and the probable mechanisms of silibinin in regulating insulin resistance in the liver of rats with non-alcoholic fatty liver
}

\author{
Jiayin Yao, Min Zhi, Xiang Gao, Pinjin Hu, Chujun Li and Xiaobo Yang \\ Department of Gastroenterology, The Sixth Affiliated Hospital, Sun Yat-Sen University, Guangzhou, Guangdong Province, \\ People's Republic of China
}

\begin{abstract}
Our previous study has shown that reduced insulin resistance (IR) was one of the possible mechanisms for the therapeutic effect of silibinin on non-alcoholic fatty liver disease (NAFLD) in rats. In the present study, we investigated the pathways of silibinin in regulating hepatic glucose production and IR amelioration. Forty-five 4- to 6-week-old male Sprague Dawley rats were divided into a control group, an HFD group (high-fat diet for 6 weeks) and an HFD + silibinin group (high-fat diet + $0.5 \mathrm{mg} \mathrm{kg}^{-1}$. day ${ }^{-1}$ silibinin, starting at the beginning of the protocol). Both subcutaneous and visceral fat was measured. Homeostasis model assessment-IR index (HOMA-IR), intraperitoneal glucose tolerance test and insulin tolerance test (ITT) were performed. The expression of adipose triglyceride lipase (ATGL) and of genes associated with hepatic gluconeogenesis was evaluated. Silibinin intervention significantly protected liver function, down-regulated serum fat, and improved IR, as shown by decreased HOMA-IR and increased ITT slope. Silibinin markedly prevented visceral obesity by reducing visceral fat, enhanced lipolysis by up-regulating ATGL expression and inhibited gluconeogenesis by down-regulating associated genes such as Forkhead box 01, phosphoenolpyruvate carboxykinase and glucose-6-phosphatase. Silibinin was effective in ameliorating IR in NAFLD rats. Reduction of visceral obesity, enhancement of lipolysis and inhibition of gluconeogenesis might be the underlying mechanisms.
\end{abstract}

Key words: Non-alcoholic fatty liver disease; Insulin resistance; Silibinin; Visceral obesity

\section{Introduction}

Non-alcoholic fatty liver disease (NAFLD), a spectrum of liver disorders ranging from simple steatosis to nonalcoholic steatohepatitis (NASH) and advanced hepatic fibrosis or even cirrhosis (1), is affecting a constantly increasing number of people all over the world $(2,3)$. Silibinin, a natural antioxidant, has long been used in various liver ailments, including NAFLD, with a marked hepatoprotective efficacy (4). However, the detailed mechanisms of action of silibinin in NAFLD are unknown. Trappoliere et al. (5) concluded that silibinin together with vitamin $E$ and phospholipids had therapeutic effects on NAFLD patients. Federico et al. (6) stated that the silibinin-vitamin E-phospholipid complex improved insulin resistance (IR) but did not describe in-depth mechanisms. For the first time in recent literature, our team used silibinin alone and not as part of a pharmacological complex for intervention. In this previous study, we indicated that mitochondrial membrane stabilization, oxidative stress inhibition, as well as IR amelioration were the essential mechanisms for the hepatoprotective effect of silibinin on NAFLD rats (7). Since IR has been widely recognized as the key mechanism in the pathogenesis of NAFLD $(8,9)$, we investigated the pathways of silibinin in IR improvement.

IR is a physiological mechanism by which the natural hormone insulin becomes less effective in reducing blood sugar (10). Perseghin et al. (11) led a 15-year observation of 2011 of 2074 Caucasian middle-aged individuals of the Cremona Study and concluded that individuals in the highest quintile of serum insulin had a $62 \%$ higher risk of cancer mortality. Additionally, confirmed by age- and sexadjusted analysis, hyperinsulinemia/IR was associated with cancer mortality independently of diabetes, visceral obesity or the metabolic syndrome. Zelber-Sagi et al. (12) showed that weight gain and baseline IR were predictors for NAFLD incidence according to an evaluation of 147 patients who did not have NAFLD at baseline but $28(19 \%)$ of whom developed NAFLD in a 7-year follow-up. Therefore, IR was

Correspondence: Min Zhi, Department of Gastroenterology, The Sixth Affiliated Hospital, Sun Yat-Sen University, 26th Yuancun the second Road, Guangzhou, Guangdong Province 510655, China. Fax: +86-020-3825-4116. E-mail: doctorzhimin@163.com 
definitely the key point in the pathogenesis of NAFLD $(13,14)$. Studying the potential action of silibinin on IR regulation has a profound significance.

Visceral obesity was supposed to be a better predictor of morbidity and mortality related to IR than general obesity measured by the body mass index. A causal relationship seemed to exist between accumulation of visceral fat and the occurrence of IR. Visceral fat acted as a large endocrine gland, excreting cytokines and adipokines, which led to IR and to a proinflammatory state, whereas subcutaneous fat might act as a protective metabolic sink (15). Besides, defects in lipid utilization via mitochondrial oxidation and lipid export also contributed to hepatic lipid build-up $(16,17)$. Disorders of blood glucose metabolism might in turn aggravate IR, resulting in the development and progress of NAFLD. Thus, we aimed to further investigate the mechanism by which silibinin improves IR in NAFLD rats, mainly from the perspective of changes in fat, lipid and glucose metabolism.

\section{Material and Methods}

\section{Ethics statement}

Our experiments were performed in conformity with $\mathrm{NIH}$ guidelines (NIH Pub. No. 85-23, revised 1996) and were approved by the Animal Care and Use Committee of the Sun Yat-Sen University (No. 20091201001). All surgical and experimental procedures were performed according to the guidelines for the care and use of animals approved by the Sun Yat-Sen University and were in accordance with the code of Ethics of EU Directive 2010/63/EU for animal experiments. All efforts were made to minimize animal suffering and to reduce the number of animals used.

\section{Animals}

Forty-five 4- to 6-week-old male Sprague Dawley rats, clear animals, were obtained from the Animal Experiment Center of the Sun Yat-Sen University. Animals were maintained on a 12:12-h artificial light-dark cycle and housed in 9 cages with 5 rats each. Food and water were available at all times except for a 12- to 16-h fasting period before the intraperitoneal glucose tolerance test (IPGTT) and insulin tolerance test (ITT). All experiments were performed in the city of Guangzhou, China.

\section{Protocol}

After a 1 week habituation, 45 Sprague Dawley rats were randomly divided into three groups of 15 rats each: control group (standard diet + intragastric distilled water); HFD group (high-fat diet + intragastric distilled water); HFD + silibinin group (high-fat diet + intragastric silibinin, $26.25 \mathrm{mg} \mathrm{kg}^{-1}$. day $^{-1}$ ). The high-fat diet, containing 20\% lard $+1 \%$ cholesterol, was provided by the Animal Experimental Center of Guangdong Province. Non-complexed silibinin was purchased from Tianjin Tianshili Pharmaceutical Co., Ltd., China, which is one of the best pharmaceutical companies in China with confirmed quality control (guarantee No. from Drug Administration of China is WS1-(X-234)2004Z). Silibinin was dissolved in distilled water in order to fully simulate the process of taking medicines by humans. We calculated the most suitable dose for rats according to the following formulas: Dose for rats $=(X \mathrm{mg} / \mathrm{kg} \times 70 \mathrm{~kg}$ $\times 0.018) / 0.2 \mathrm{~kg}$ or simplified as $6.3 \mathrm{X} \mathrm{mg} / \mathrm{kg}(\mathrm{X}=$ the effective dose for man; $70 \mathrm{~kg}=$ the standard weight for man; 0.018 = ratio of the equivalent dose for man and rats based on body surface area; $0.2 \mathrm{~kg}=$ the standard weight for rat) (18).

\section{Necropsy}

At the end of the 6th week, after the application of the IPGTT and ITT, rats were anesthetized and blood samples were collected into tubes by cardiac puncture for hepatic enzyme and blood fat assay. Body weight was recorded. Retroperitoneal and inguinal fat was isolated and weighed. Part of lipid tissue was frozen in liquid nitrogen for RT-PCR. Liver tissue was rapidly dissected, cut and fixed in $10 \%$ formaldehyde saline solution for histological analysis. The rest was snap frozen in liquid nitrogen, and then stored at $-80^{\circ} \mathrm{C}$ for RT-PCR.

\section{Liver histology}

Liver specimens were stained with hematoxylin-eosin for evaluation of liver histology. Additional sections were stained with Sudan III for lipid observation. An expert pathologist evaluated the stained samples in a blind fashion and evaluated the NAFLD activity score (NAS).

\section{IPGTT, ITT and homeostasis model assessment-IR (HOMA-IR)}

To assess glucose tolerance, rats were given an intraperitoneal injection of glucose at the dose of $2 \mathrm{~g} / \mathrm{kg}$ after a 16-h fast. Blood glucose was tested with a glucose monitor (Johnson \& Johnson Services, Inc., USA) at 0, 30,60 , and $120 \mathrm{~min}$ right after injection of the glucose load (19). The ROC curve was constructed and the area under the ROC curve (AUC) was calculated using the Origin 6.0 software (Microsoft). After the IPGTT, rats were again fasted for $12 \mathrm{~h}$. Insulin (Humulin R, Novo Nordisk, Denmark) was injected at the dose of $1 \mathrm{IU} / \mathrm{kg}$ and blood glucose was tested at 0, 15, 30 min after injection (20). Fasting serum insulin was measured using a radioimmunoassay kit (Dainabot Co., Ltd., Japan) and HOMA-IR was calculated (HOMA-IR = [fasting glucose $(\mathrm{mM}) \times$ fasting insulin $(\mu \mathrm{U} / \mathrm{mL})] / 22.5)$ (21).

\section{Determination of serum hepatic enzymes and serum lipid content}

Blood samples were collected into tubes by cardiac puncture. Serum content of aspartate aminotransferase (AST), alanine aminotransferase (ALT), total cholesterol (TC), and triglycerides (TG) was determined using an Olympus AU400 Clinical Chemistry analyzer (Japan). 
Table 1. Primers and product size for each target gene.

\begin{tabular}{|c|c|c|c|c|}
\hline Gene & Primers & Length $(\mathrm{kp})$ & Cycles & $\begin{array}{c}\text { Annealing } \\
\text { temperature }\left({ }^{\circ} \mathrm{C}\right)\end{array}$ \\
\hline \multirow[t]{2}{*}{ ATGL } & Forward: 5'-СТСАТТССТССТАСАСТССАА-3' & 503 & 35 & 58 \\
\hline & Reverse: 5'-CGTCTGCTCTTTCATCCACCA-3' & & & \\
\hline \multirow[t]{2}{*}{ FoxO1 } & Forward: 5'-GTCCACAACATCTTCAACTA-3' & 302 & 36 & 58 \\
\hline & Reverse: 5'-ACTTAATTCGCTATCCTGAAC-3' & & & \\
\hline \multirow[t]{2}{*}{ PEPCK } & Forward: 5'-CCATTGCGGATATCATCTAA-3' & 720 & 40 & 60 \\
\hline & Reverse: 5'-ACAGCATTGTGCCTCTAGCC-3' & & & \\
\hline \multirow[t]{2}{*}{ G-6-Pase } & Forward: 5'-TCCACCTTGACACCACATTC-3' & 546 & 38 & 58 \\
\hline & Reverse: 5'-CTCACTTACTAGCATTCAAC-3' & & & \\
\hline \multirow[t]{2}{*}{$\beta$-actin } & Forward: 5'-CGTGCGTGACATTAAGAAG-3' & 305 & 30 & 56 \\
\hline & Reverse: 5'-GGCATAGAGGTCTTAGATG-3' & & & \\
\hline
\end{tabular}

ATGL $=$ adipose triglyceride lipase; FoxO1 = Forkhead box 01; PEPCK $=$ phosphoenolpyruvate carboxykinase; G-6-Pase $=$ glucose-6-phosphatase.

\section{Isolation of total RNA and RT-PCR analysis}

All the rats in each group were sampled for RT-PCR analysis. Total RNA was extracted from liver and adipose tissue using TRIzol (Qiagen, USA) according to manufacturer instructions. A 500-ng amount of total RNA was used for cDNA synthesis and $1 \mu \mathrm{L}$ of each reverse transcription product was added to $9 \mu \mathrm{L}$ MasterMix reaction (containing buffer, SYGB, Hotstart Taq polymerase, dNTPs), $0.2 \mu \mathrm{L}$ $25 \mathrm{mM}$ dNTPs, $0.5 \mu \mathrm{L} 25 \mu \mathrm{M}$ corresponding primers, and

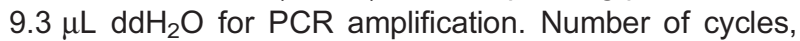
annealing temperature for each primer pair and the sequences of the primers used are listed in Table 1. The relative levels of the target mRNAs were normalized to the corresponding levels of $\beta$-actin mRNA in the same cDNA sample using a standard curve method recommended in the LightCycler Software version 3.5 (Roche Molecular Diagnostics Systems, France).

\section{Statistical analysis}

Data are reported as means \pm SD. Data were analyzed by one-way analysis of variance (ANOVA), followed by the Bonferroni multiple comparisons test. Statistical significance for expression analysis was also assessed by ANOVA and the differences identified were tested using the unpaired Student $t$-test. For parameters showing non-normal distribution such as HOMA-IR, the
Wilcoxon rank sum test was performed. The level of significance was set at $<5 \%$. All statistical analyses were performed using SPSS version 13.0 (IBM Inc., USA).

\section{Results}

\section{Weight of adipose tissue at different sites and visceral fat/body weight ratio}

At the end of the 6th week, the weight of subcutaneous fat (inguinal fat) and visceral fat (retroperitoneal fat) was significantly increased in the HFD group compared to control ( $P<0.05 ;$ Table 2$)$. In addition, there was a significant increase in the visceral fat/body weight ratio in the HFD group, which proved the development of abdominal obesity induced by the high-fat diet. In the HFD + silibinin group, the weight of visceral fat as well as visceral fat/body weight ratio were noticeably less than the HFD groups, showing the benefits of silibinin in improving visceral obesity (Table 2). Compared to the HFD group, subcutaneous fat tended to be reduced in the HFD + silibinin group, although the difference was not statistically significant.

\section{Serum fat and hepatic enzyme}

Serum fat including TG and TC increased in the HFD group, as also did hepatic enzymes such as ALT and AST,

Table 2. Weight of fat at different sites, body weight and visceral fat/body weight ratio of rats.

\begin{tabular}{lcccc}
\hline Groups & Body weight $(\mathrm{g})$ & $\begin{array}{c}\text { Visceral fat } \\
\text { (retroperitoneal fat; g) }\end{array}$ & $\begin{array}{c}\text { Subcutaneous fat } \\
\text { (inguinal fat; g) }\end{array}$ & $\begin{array}{c}\text { Visceral fat/body } \\
\text { weight ratio }(\%)\end{array}$ \\
\hline Control & $295.3 \pm 13.1^{*}$ & $17.8 \pm 2.7^{*}$ & $7.6 \pm 1.9^{*}$ & $6.0^{*}$ \\
HFD & $370.4 \pm 11.9$ & $23.6 \pm 2.6$ & $9.9 \pm 2.1$ & 6.4 \\
HFD + silibinin & $333.7 \pm 13.4^{*}$ & $19.9 \pm 3.3^{*}$ & $8.9 \pm 2.3$ & $5.9^{*}$ \\
\hline
\end{tabular}

Data are reported as means \pm SD for 15 rats. HFD $=$ high-fat diet. ${ }^{*} \mathrm{P}<0.05$ vs HFD group (ANOVA followed by the Bonferroni multiple comparisons test). 
Table 3. Serum fat, hepatic enzymes and HOMA-IR of the rats in each group.

\begin{tabular}{lcccccc}
\hline Groups & TG $(\mathrm{mM})$ & TC $(\mathrm{mM})$ & ALT $(\mathrm{U} / \mathrm{L})$ & AST $(\mathrm{U} / \mathrm{L})$ & HOMA-IR & K ITT \\
\hline Control & $1.08 \pm 0.42^{*}$ & $1.62 \pm 0.37^{*}$ & $251 \pm 47.34^{*}$ & $196 \pm 52.23^{*}$ & $1.10 \pm 0.39^{*}$ & 0.27 \\
HFD & $1.82 \pm 0.47$ & $2.69 \pm 0.65$ & $449 \pm 56.12$ & $472 \pm 71.23$ & $3.46 \pm 1.20$ & 0.14 \\
HFD + silibinin & $1.39 \pm 0.50^{*}$ & $2.14 \pm 0.41^{*}$ & $368 \pm 54.37^{*}$ & $304 \pm 63.10^{*}$ & $1.35 \pm 1.77^{*}$ & 0.23 \\
\hline
\end{tabular}

Data are reported as means \pm SD for 15 rats. $T G=$ triglyceride; $T C=$ total cholesterol; $A L T=$ alanine aminotransferase; $A S T=$ aspartate aminotransferase; HOMA-IR = homeostasis model assessment-insulin resistance index; $\mathrm{K}_{\mathrm{ITT}}=$ insulin tolerance test slope; $\mathrm{HFD}=$ high-fat diet. ${ }^{*} \mathrm{P}<0.05$ vs HFD group (ANOVA followed by the Bonferroni multiple comparisons test and the Wilcoxon rank sum test).

indicating damage to hepatic function. Reduced levels of serum fat and hepatic enzymes were observed after pharmaceutical intervention, indicating that silibinin was effective in reducing not only visceral fat, but also serum fat and finally led to improved liver function (Table 3).

\section{Pathological changes of rat liver in each group}

The liver of HFD rats showed typical cytological ballooning and lobular inflammation with deranged liver cell cords, confirming the successful establishment of the animal model (Figure 1, panel $\mathrm{M}_{1}$ ). Administration of silibinin for 6 weeks significantly improved fatty degeneration and inflammation, manifesting as less cytological ballooning, relatively regularly arranged cell cords, and scarcely any lobular inflammation (Figure 1 , panel $S_{1}$ ).
This revealed the benefits of silibinin in treating NAFLD, as shown by improved pathological changes. Fat diffusely accumulated in hepatic tissue in the HFD group (Figure 1, panel $\mathrm{M}_{2}$ ). When stained with Sudan III, the cytochylema in the hepatic cell was observed as salmon pink. After silibinin intervention, fat accumulation was reduced, with a smaller salmon pink cytochylema in the hepatocyte (Figure 1, panel $\mathrm{S}_{2}$ ).

The NAS was calculated according to the definition of the Pathology Committee of the NASH Clinical Research Network (22). Although NAS was originally established and validated in human adult and pediatric patients, recent animal studies have used this score to assess NASH (23). An NAFLD activity score $\geqslant 4$ had optimal sensitivity and specificity for predicting steatohepatitis,
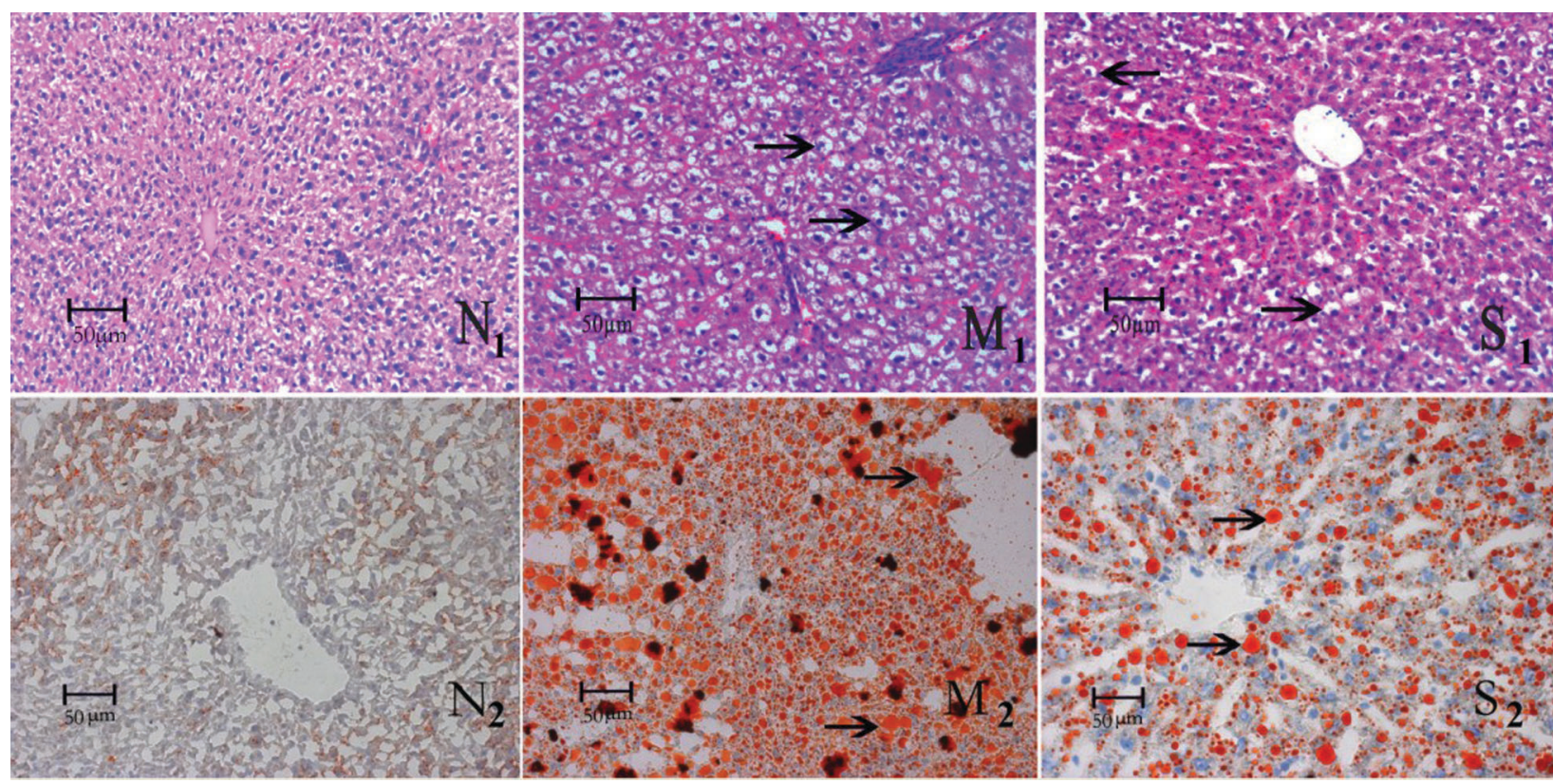

Figure 1. Pathological changes of rat liver stained with hematoxylin-eosin and Sudan III in each group. The micrographs show a mass of large fat granules (black arrows in Panel $M_{1}$ ), which represent steatosis in the liver of the group receiving a high-fat diet (HFD) for 6 weeks. Improvement could be seen in the silibinin group with fewer and smaller fat granules (black arrows in Panel $\mathrm{S}_{1}$ ) and relatively regularly arranged cell cords. Pathologic evaluation showed more and larger fat granules stained salmon pink by Sudan III in the HFD group (black arrows in Panel $\mathrm{M}_{2}$ ). Fewer and smaller fat granules could be seen in the group treated with silibinin (black arrows in Panel $\left.\mathrm{S}_{2}\right) \cdot \mathrm{N}=$ control group. 
and was the recommended value for admission to an interventional trial for NASH (24). The median score results were 0 (0-3) for controls, 6.0 (4-8) for the HFD group ( $\mathrm{P}<0.05$ vs control group), and $3.2(2-5)$ for the HFD + silibinin group ( $P<0.05$ vs HFD group).

\section{IPGTT}

HFD rats showed obviously higher blood glucose levels induced by the high-fat diet at each time point compared to control in the IPGTT ( $P<0.05$ or $P<0.01)$. The AUC for the HFD group was 2100 , nearly twice that for the control group, which was 1100 . According to the diagnostic criteria for diabetes in experimental rats, an AUC larger than the standard values plus triple standard deviation permitted us to diagnose diabetes in rats (25). In our experiment, diabetes induced by the high-fat diet was detected in HFD rats. After silibinin intervention, blood glucose was significantly decreased $(P<0.05)$ as shown by the IPGTT and AUC $(P<0.05)$ and a diagnosis of diabetes could not be established in the HFD + silibinin group (Figure 2).

\section{Changes in insulin sensitivity}

We performed the HOMA-IR and ITT, which represent the changes in insulin sensitivity. HFD rats showed a marked increase in HOMA-IR and a decrease in the ITT slope $\left(\mathrm{K}_{\mathrm{ITT}}\right)$, demonstrating typical IR induced by the highfat diet. In the HFD + silibinin group, HOMA-IR decreased and $\mathrm{K}_{\mathrm{ITT}}$ increased compared to the HFD group, showing reduced $I R$ induced by pharmaceutical intervention (Table 3, Figure 3).

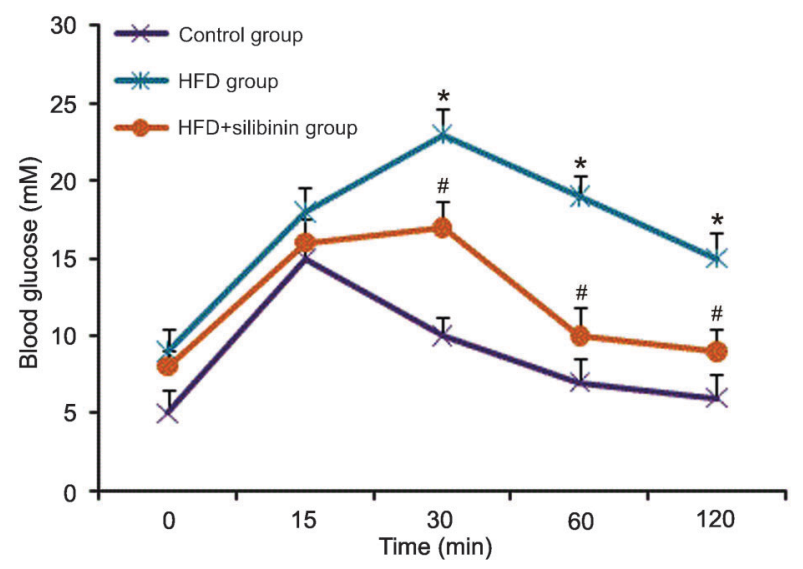

Figure 2. Changes of blood glucose during the intraperitoneal glucose tolerance test (IPGTT) in each group. Fasting glucose and the peak blood glucose value during the IPGTT were markedly higher in the high-fat diet (HFD) group than in the control group and HFD + silibinin group, which showed impairment of sugar tolerance and the presence of insulin resistance. ${ }^{*} \mathrm{P}<0.05$ for the control group vs HFD group; ${ }^{\#} \mathrm{P}$ $<0.05$ for the HFD + silibinin group vs the HFD group (ANOVA followed by the Bonferroni multiple comparisons test).

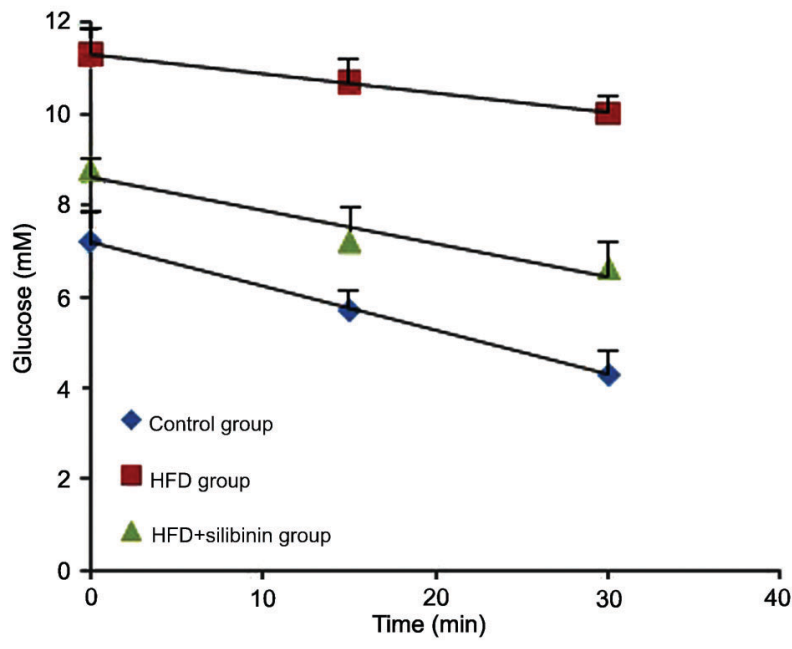

Figure 3. Insulin tolerance test (ITT) applied to each group. The ITT slope $\left(\mathrm{K}_{\mathrm{ITT}}\right)$ represents the degree of insulin resistance. The lower the $\mathrm{K}_{\mathrm{ITT}}$, the more serious the insulin resistance. The highfat diet (HFD) group showed the lowest $\mathrm{K}_{\mathrm{ITT}}$, which was increased in the silibinin group (HFD + silibinin).

\section{Expression of adipose triglyceride lipase (ATGL) in adipose tissue and expression of hepatic gluconeogenesis-associated genes in liver tissue}

Induced by the high-fat diet, HFD rats showed a decreased tendency in mRNA expression of ATGL in adipose tissue, although without statistical significance. A significant increase in ATGL expression was found in the HFD + silibinin group $(P<0.01)$. Expression of hepatic gluconeogenesis associated genes such as Forkhead box O1 (FoxO1), phosphoenolpyruvate carboxykinase (PEPCK) and glucose 6-phosphatase (G-6-Pase) was increased in the HDF group and decreased in the HFD + silibinin group, respectively $(P<0.05$; Figure 4$)$.

\section{Discussion}

\section{NAFLD rat model was successfully established}

We established an NAFLD rat model by feeding a highfat diet for 6 weeks. This was confirmed by hepatopathological findings, and we further found NASH in NAFLD rats with an NAFLD activity score $>4$. Rats in the HFD group showed high levels of hepatic enzymes which, according to Bolum et al. (26), are supposed to be additional markers of IR. These investigators also suggested that these subjects must be considered to be potentially affected not only by hepatic but also by multisystem diseases through altered insulin sensitivity (26). In addition, NAFLD rats showed a sharp gain in body weight and adipose tissue weight, a marked increase in HOMA-IR and a decrease in $\mathrm{K}_{\mathrm{ITT}}$, which demonstrated that abdominal obesity and IR were well established. Furthermore, we found diabetes in NAFLD rats since the AUC was larger than the standard values plus triple standard deviation (25). We proved that 

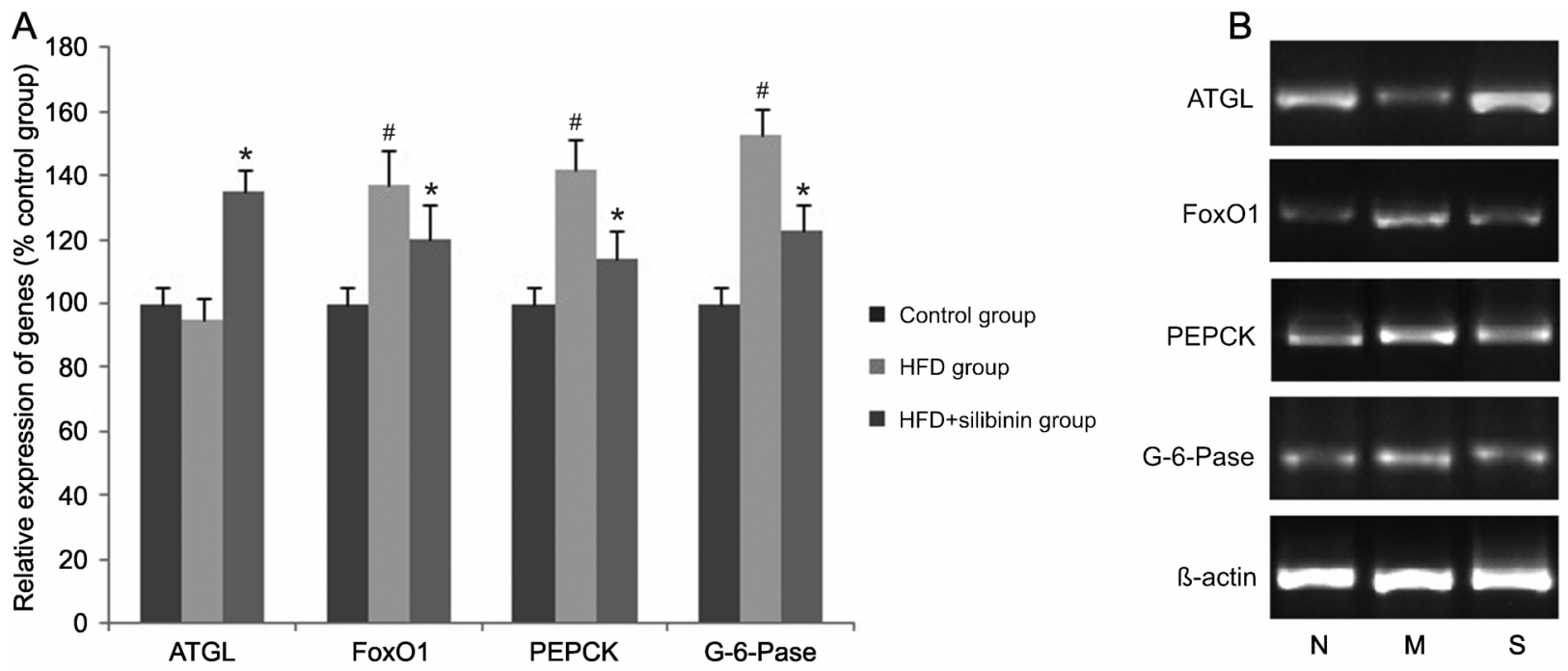

Figure 4. Relative expression of adipose triglyceride lipase (ATGL) in adipose tissue and hepatic gluconeogenesis-associated genes in each group. Expression of ATGL, the rate-limiting gene in lipolysis, was decreased in the high-fat diet (HFD) group, indicating inhibition of lipolysis induced by the high-fat diet. In contrast, increased expression of Forkhead box O1 (FoxO1), phosphoenolpyruvate carboxykinase (PEPCK) and glucose-6-phosphatase (G-6-Pase) was found in the HFD group, implying enhancement of gluconeogenesis. Silibinin enhanced the expression of ATGL, but decreased that of FoxO1, PEPCK and G-6-Pase. *P $<0.05$ vs the HFD group; ${ }^{\mathrm{P}}<0.05$ vs the control group (ANOVA followed by the Bonferroni multiple comparisons test). Panel B, RT-PCR: $\mathrm{N}=$ control group; $M=$ HFD group; $S=H F D+$ silibinin group.

NAFLD was strongly associated with metabolic syndrome and type 2 diabetes, in the pathogenesis of which IR played the core role.

\section{Silibinin reduced IR by reducing visceral fat}

It is widely recognized that visceral obesity is one of the strongest risk factors associated with IR and type 2 diabetes $(27,28)$. The more visceral fat that is present, the more serious is IR. Riserus et al. (29) proposed that sagittal abdominal diameter was a better correlate of IR and hyperproinsulinemia than other anthropometric measures in clinical trials evaluating insulin sensitizers. Pietilainen et al. (30) concluded that acquired obesity and visceral adipose tissue content were positively correlated with IR. In our HFD rats, we observed obesity, IR and even diabetes. After intervention with silibinin, the body weights of the rats declined sharply, indicating the weight-reducing effect of silibinin. We also focused on the ratio of visceral fat weight to body weight, which represents the severity of visceral obesity. Our results showed that silibinin effectively reduced visceral fat and led to amelioration of visceral obesity, which we proposed to be one of the mechanisms of action of silibinin for IR improvement.

\section{Silibinin improved IR by enhancing lipolysis}

Samuel et al. (31) concluded that liver lipid deposition leads to IR. They observed a 3-fold increase in hepatic lipid content without peripheral tissue IR or increased free fatty acids (FFA) in rats treated on a short-term basis (3 days) with a high-fat diet, which proved that hepatic IR did not occur secondary to an increase of FFA or peripheral IR. However, hepatic insulin sensitivity was found to decrease gradually when the period of intake of the highfat diet was prolonged. The authors further observed that hepatic lipid deposition could activate the protein kinase $\mathrm{C}$ and $\mathrm{JUN} \mathrm{NH}_{2}$-terminal kinase pathways, both of which inhibited phosphorylation of the insulin receptor substrate, blocked the hepatocellular insulin signaling pathway and finally led to IR (31). Therefore, reduction of hepatic fat deposition contributed to the amelioration of IR.

ATGL was responsible for the rate-limiting, initial step of lipolysis (32). The regulation of ATGL expression and activity by hormonal or nutritional factors is multifactorial and is not completely understood. ATGL knock-out mice showed defective thermogenesis, increased glucose tolerance and impaired insulin sensitivity, indicating that the enzyme played a role in regulating energy homeostasis $(33,34)$. In our study, rats fed the high-fat diet showed a tendency to a decreased gene expression of ATGL in adipose tissue, although without statistical significance. ATGL expression markedly increased after silibinin intervention. Thus, silibinin up-regulated ATGL expression, enhanced lipolysis, and further reduced visceral obesity and hepatic lipid deposition, which ultimately ameliorated IR. Undoubtedly, the precise regulation of ATGL expression by silibinin should be further documented. 
Silibinin reduced IR by inhibiting gluconeogenesis

Hepatic IR is supposed to play a core role in the pathogenesis of type 2 diabetes (35), resulting in the reduced ability of insulin to stimulate glucose uptake into peripheral tissue and to regulate hepatic glucose production (36). Glucose metabolism in the liver consists of gluconeogenesis and glycogenolysis. Based on our previous study, silibinin was effective in stabilizing the mitochondrial membrane, enhancing oxidation and glycogenolysis (7). We propose that silibinin reduced IR and suppressed glucose production by inhibiting gluconeogenesis. G-6-Pase and PEPCK, the key enzymes in the process of gluconeogenesis, were found to be upregulated in IR and diabetes $(37,38)$. Our data showed down-regulation of the expression of G-6-Pase and PEPCK by silibinin intervention, indicating that silibinin was effective in inhibiting gluconeogenesis and reducing glucose production mainly by suppressing expression of key enzymes, which consequently led to IR improvement.

FoxO1 plays an important role in mediating the effect of insulin on hepatic metabolism (39). Increased FoxO1 activity resulted in up-regulation of hepatic peroxisome proliferator-activated receptor-gamma

\section{References}

1. Argo $\mathrm{CK}$, Caldwell SH. Epidemiology and natural history of non-alcoholic steatohepatitis. Clin Liver Dis 2009; 13: 511531, doi: 10.1016/j.cld.2009.07.005.

2. Amarapurkar DN, Hashimoto E, Lesmana LA, Sollano JD, Chen PJ, Goh KL. How common is non-alcoholic fatty liver disease in the Asia-Pacific region and are there local differences? J Gastroenterol Hepatol 2007; 22: 788-793, doi: 10.1111/j.1440-1746.2007.05042.x.

3. de Silva HJ, Dassanayake AS. Non-alcoholic fatty liver disease: confronting the global epidemic requires better awareness. J Gastroenterol Hepatol 2009; 24: 1705-1707, doi: 10.1111/j.1440-1746.2009.06026.x.

4. Loguercio C, Festi D. Silybin and the liver: from basic research to clinical practice. World J Gastroenterol 2011; 17: 2288-2301, doi: 10.3748/wjg.v17.i18.2288.

5. Trappoliere M, Federico A, Tuccillo C, de Sio I, Di Leva A, Niosi $M$, et al. [Effects of a new pharmacological complex (silybin + vitamin-E + phospholipids) on some markers of the metabolic syndrome and of liver fibrosis in patients with hepatic steatosis. Preliminary study]. Minerva Gastroenterol Dietol 2005; 51: 193-199.

6. Federico A, Trappoliere M, Tuccillo C, de Sio I, Di Leva A, Del Vecchio Blanco C, et al. A new silybin-vitamin Ephospholipid complex improves insulin resistance and liver damage in patients with non-alcoholic fatty liver disease: preliminary observations. Gut 2006; 55: 901-902, doi: 10.1136/gut.2006.091967.

7. Yao J, Zhi M, Minhu C. Effect of silybin on high-fat-induced fatty liver in rats. Braz J Med Biol Res 2011; 44: 652-659.

8. Hallsworth K, Fattakhova G, Hollingsworth KG, Thoma C Moore S, Taylor R, et al. Resistance exercise reduces liver fat and its mediators in non-alcoholic fatty liver disease coactivator-1beta, fatty acid synthase, and acetyl CoA carboxylase expression, accounting for increased hepatic fat infiltration (40). Our results showed that the expression of FoxO1 was markedly down-regulated by silibinin. Reduced expression of FoxO1 led to the inhibition of gluconeogenesis and to a gain of the ability to regulate hepatic metabolism.

$\mathrm{IR}$ is universally acknowledged to play a key role in the pathogenesis of NAFLD. Silibinin, exerting a marked therapeutic effect on NAFLD rats, was found to be effective in ameliorating IR mainly by reducing visceral fat, up-regulating ATGL expression to enhance lipolysis, and inhibiting gluconeogenesis by down-regulating associated genes.

\section{Acknowledgments}

Research supported by a grant from the National Natural Science Foundation of China (\#30600845) and a grant from the Federal Office of Public Health of Guangdong Province of China (\#B2006135). The funders had no role in study design, data collection or analysis, decision to publish, or preparation of the manuscript. independent of weight loss. Gut 2011; 60: 1278-1283, doi: 10.1136/gut.2011.242073.

9. Jacobs M, van Greevenbroek MM, van der Kallen CJ, Ferreira I, Feskens EJ, Jansen EH, et al. The association between the metabolic syndrome and alanine amino transferase is mediated by insulin resistance via related metabolic intermediates (the Cohort on Diabetes and Atherosclerosis Maastricht [CODAM] study). Metabolism 2011; 60: 969-975, doi: 10.1016/j.metabol.2010.09.006.

10. Pagel-Langenickel I, Bao J, Pang L, Sack MN. The role of mitochondria in the pathophysiology of skeletal muscle insulin resistance. Endocr Rev 2010; 31: 25-51, doi: 10.1210/er.2009-0003.

11. Perseghin G, Calori G, Lattuada G, Ragogna F, Dugnani E, Garancini MP, et al. Insulin resistance/hyperinsulinemia and cancer mortality: the Cremona study at the 15th year of follow-up. Acta Diabetol 2012; 49: 421-428, doi: 10.1007/ s00592-011-0361-2.

12. Zelber-Sagi S, Lotan R, Shlomai A, Webb M, Harrari G, Buch $A$, et al. Predictors for incidence and remission of NAFLD in the general population during a seven-year prospective follow-up. J Hepatol 2012; 56: 1145-1151, doi: 10.1016/j.jhep.2011.12.011.

13. Svegliati-Baroni $G$, Bugianesi $E$, Bouserhal $T$, Marini $F$, Ridolfi $F$, Tarsetti $F$, et al. Post-load insulin resistance is an independent predictor of hepatic fibrosis in virus $C$ chronic hepatitis and in non-alcoholic fatty liver disease. Gut 2007; 56: 1296-1301, doi: 10.1136/gut.2006.107946.

14. Leclercq IA, Da Silva Morais A, Schroyen B, Van Hul N, Geerts A. Insulin resistance in hepatocytes and sinusoidal liver cells: mechanisms and consequences. $J$ Hepatol 2007; 47: 142-156, doi: 10.1016/j.jhep.2007.04.002. 
15. Korsic M, Fister K, Ivankovic D, Jelcic J. [Visceral obesity]. Lijec Vjesn 2011; 133: 284-287.

16. Smith BW, Adams LA. Non-alcoholic fatty liver disease. Crit Rev Clin Lab Sci 2011; 48: 97-113, doi: 10.3109/ 10408363.2011.596521.

17. Mollica MP, Lionetti L, Moreno M, Lombardi A, De Lange $P$, Antonelli $A$, et al. 3,5-Diiodo-L-thyronine, by modulating mitochondrial functions, reverses hepatic fat accumulation in rats fed a high-fat diet. J Hepatol 2009; 51: 363-370, doi: 10.1016/j.jhep.2009.03.023.

18. Qi C. Chinese traditional medicine pharmacological research methodology. Guangzhou: People's Medical Publishing Company; 2006.

19. Yong J, Rasooly J, Dang H, Lu Y, Middleton B, Zhang Z, et al. Multimodality imaging of beta-cells in mouse models of type 1 and 2 diabetes. Diabetes 2011; 60: 1383-1392, doi: 10.2337/db10-0907.

20. Fan R, Kang Z, He L, Chan J, Xu G. Exendin-4 improves blood glucose control in both young and aging normal nondiabetic mice, possible contribution of beta cell independent effects. PLoS One 2011; 6: e20443, doi: 10.1371/journal.pone.0020443.

21. Bonora E, Targher G, Alberiche M, Bonadonna RC, Saggiani F, Zenere MB, et al. Homeostasis model assessment closely mirrors the glucose clamp technique in the assessment of insulin sensitivity: studies in subjects with various degrees of glucose tolerance and insulin sensitivity. Diabetes Care 2000; 23: 57-63, doi: 10.2337/diacare.23.1.57.

22. Kleiner DE, Brunt EM, Van Natta M, Behling C, Contos MJ, Cummings OW, et al. Design and validation of a histological scoring system for nonalcoholic fatty liver disease. Hepatology 2005; 41: 1313-1321, doi: 10.1002/hep.20701.

23. Kuwashiro S, Terai S, Oishi T, Fujisawa K, Matsumoto T, Nishina $\mathrm{H}$, et al. Telmisartan improves nonalcoholic steatohepatitis in medaka (Oryzias latipes) by reducing macrophage infiltration and fat accumulation. Cell Tissue Res 2011; 344: 125-134, doi: 10.1007/s00441-011-1132-7.

24. Hjelkrem M, Stauch C, Shaw J, Harrison SA. Validation of the non-alcoholic fatty liver disease activity score. Aliment Pharmacol Ther 2011; 34: 214-218, doi: 10.1111/j.13652036.2011.04695.x.

25. Burcelin R, Crivelli V, Dacosta A, Roy-Tirelli A, Thorens B. Heterogeneous metabolic adaptation of $\mathrm{C} 57 \mathrm{BL} / 6 \mathrm{~J}$ mice to high-fat diet. Am J Physiol Endocrinol Metab 2002; 282: E834-E842.

26. Bolum T, Kolaric B, Duvnjak L, Duvnjak M. Nonalcoholic fatty liver disease markers are associated with insulin resistance in type 1 diabetes. Dig Dis Sci 2011; 56: 36553663, doi: 10.1007/s10620-011-1807-7.

27. Feng $B$, Jiao $P$, Nie $Y, \operatorname{Kim} T$, Jun $D$, van Rooijen $N$, et al. Clodronate liposomes improve metabolic profile and reduce visceral adipose macrophage content in diet-induced obese mice. PLoS One 2011; 6: e24358, doi: 10.1371/journal.pone.0024358.

28. Votruba SB, Jensen MD. Insulin sensitivity and regional fat gain in response to overfeeding. Obesity 2011; 19: 269-275, doi: $10.1038 /$ oby.2010.274.

29. Riserus U, Arnlov J, Brismar K, Zethelius B, Berglund L,
Vessby B. Sagittal abdominal diameter is a strong anthropometric marker of insulin resistance and hyperproinsulinemia in obese men. Diabetes Care 2004; 27: 2041-2046, doi: 10.2337/diacare.27.8.2041

30. Pietilainen $\mathrm{KH}$, Naukkarinen J, Rissanen A, Saharinen J, Ellonen $\mathrm{P}$, Keranen $\mathrm{H}$, et al. Global transcript profiles of fat in monozygotic twins discordant for BMI: pathways behind acquired obesity. PLoS Med 2008; 5: e51, doi: 10.1371/ journal.pmed.0050051.

31. Samuel VT, Liu ZX, Qu X, Elder BD, Bilz S, Befroy D, et al. Mechanism of hepatic insulin resistance in non-alcoholic fatty liver disease. J Biol Chem 2004; 279: 32345-32353, doi: $10.1074 / \mathrm{jbc}$.M313478200.

32. Etschmaier K, Becker T, Eichmann TO, Schweinzer C, Scholler M, Tam-Amersdorfer C, et al. Adipose triglyceride lipase affects triacylglycerol metabolism at brain barriers. $J$ Neurochem 2011; 119: 1016-1028, doi: 10.1111/j.14714159.2011.07498.x.

33. Huijsman E, van de Par C, Economou C, van der Poel C, Lynch GS, Schoiswohl G, et al. Adipose triacylglycerol lipase deletion alters whole body energy metabolism and impairs exercise performance in mice. Am J Physiol Endocrinol Metab 2009; 297: E505-E513, doi: 10.1152/ ajpendo.00190.2009.

34. Zechner R, Kienesberger PC, Haemmerle G, Zimmermann $\mathrm{R}$, Lass $\mathrm{A}$. Adipose triglyceride lipase and the lipolytic catabolism of cellular fat stores. J Lipid Res 2009; 50: 3-21, doi: 10.1194/jlr.R800031-JLR200.

35. Lee HY, Birkenfeld AL, Jornayvaz FR, Jurczak MJ, Kanda S, Popov V, et al. Apolipoprotein CIII overexpressing mice are predisposed to diet-induced hepatic steatosis and hepatic insulin resistance. Hepatology 2011; 54: 16501660, doi: 10.1002/hep.24571.

36. Kim SP, Ellmerer M, Van Citters GW, Bergman RN. Primacy of hepatic insulin resistance in the development of the metabolic syndrome induced by an isocaloric moderate-fat diet in the dog. Diabetes 2003; 52: 24532460, doi: 10.2337/diabetes.52.10.2453.

37. Cao R, Cronk ZX, Zha W, Sun L, Wang X, Fang Y, et al. Bile acids regulate hepatic gluconeogenic genes and farnesoid $X$ receptor via $\mathrm{G}($ alpha)i-protein-coupled receptors and the AKT pathway. J Lipid Res 2010; 51: 2234-2244, doi: 10.1194/jlr.M004929.

38. Kabir M, Catalano KJ, Ananthnarayan S, Kim SP, Van Citters GW, Dea MK, et al. Molecular evidence supporting the portal theory: a causative link between visceral adiposity and hepatic insulin resistance. Am J Physiol Endocrinol Metab 2005; 288: E454-E461, doi: 10.1152/ ajpendo.00203.2004

39. Nagashima T, Shigematsu N, Maruki R, Urano $Y$, Tanaka H, Shimaya $A$, et al. Discovery of novel forkhead box 01 inhibitors for treating type 2 diabetes: improvement of fasting glycemia in diabetic $\mathrm{db} / \mathrm{db}$ mice. Mol Pharmacol 2010; 78: 961-970, doi: 10.1124/mol.110.065714.

40. Qu S, Altomonte J, Perdomo G, He J, Fan Y, Kamagate A, et al. Aberrant Forkhead box $\mathrm{O} 1$ function is associated with impaired hepatic metabolism. Endocrinology 2006; 147: 5641-5652, doi: 10.1210/en.2006-0541. 